\title{
La epistaxis como efecto secundario del tratamiento con oxibutinina en la hiperactividad vesical
}

\section{Epistaxis as a side effect of the treatment of bladder hyperactivity with oxybutynin}

\author{
A. Molina, A. Pérez, J. Pisón, L. Ayuso
}

\section{Sr. Director:}

El tratamiento con oxibutinina de los pacientes pediátricos con alteraciones funcionales vesicales es muy frecuente. La vejiga hiperactiva representa un $18 \%$ de los diagnósticos de los niños que son sometidos a cistomanometría en la consulta de Exploraciones Funcionales del Complejo Hospitalario de Navarra. Pero aún son más numerosos los pacientes que, atendiendo exclusivamente a criterios clínicos definidos por la frecuencia miccional (más de 7 micciones al día), un escaso volumen miccional máximo (dependiente de la edad) y la existencia de síntomas sugestivos de urgencia miccional, reciben empíricamente tratamiento anticolinérgico oral.

El fármaco más empleado es la oxibutinina debido a su fácil dosificación y precio asequible, pero conlleva el riesgo de efectos secundarios conocidos (Tabla 1) y frecuentemente evitables si se inicia el tratamiento con dosis bajas para ir subiéndolas progresivamente según la aceptación del enfermo y la respuesta terapéutica.
Tabla 1. Efectos secundarios de la oxibutinina.

Sensación de sequedad en la boca*
Visión borrosa*
Ojos, nariz o piel seca
Enrojecimiento facial*
Dolor de estómago*
Estreñimiento*
Diarrea
Náuseas*
Acidez estomacal
Gases
Cambios en la capacidad de degustar los alimentos
Tos, epistasxis, faringitis
Dolor de cabeza
Mareos
Debilidad
Confusión
Somnolencia*
Dificultad para quedarse dormido o permanecer
dormido
Nerviosismo
Desmayos
Vértigo*
Inflamación (hinchazón) de las manos, brazos, pies,
tobillos o pantorrillas
Dolor en la espalda o en las articulaciones
Mayor frecuencia al orinar
Dificultad para orinar*
Sarpullido (erupciones en la piel)
Ritmo cardíaco más rápido que lo normal, irregular,
o palpitaciones
*Frecuentes

${ }^{*}$ Frecuentes
Servicio de Cirugía Pediátrica y Unidad de Exploraciones Funcionales. Complejo Hospitalario de Navarra B. Pamplona (Navarra).

Recepción: 25 de noviembre de 2012

Aceptación provisional: 21 de enero de 2013

Aceptación definitiva: 1 de febrero de 2013

\section{Correspondencia:}

Ada Molina Caballero

Servicio de Cirugía Pediátrica y Unidad de

Exploraciones Funcionales

Complejo Hospitalario de Navarra

C/ Irunlarrea, 3

31008 Pamplona (Navarra)

adyemoca@yahoo.com 
El caso que nos ocupa corresponde a un enfermo de 7 años con una historia de manchado fecal y fugas de orina nocturnas y diurnas de 3 años de evolución, agravada tras la separación de los padres. Aunque realiza deposiciones a diario y éstas son abundantes y de consistencia blanda, mantiene tanto pequeños manchados fecales como deposiciones completas inadecuadas durante el día. La enuresis nocturna es ocasional, pero las fugas de orina diurnas son continuas y atribuidas a falta de atención. Los padres describen crisis de urgencia miccional ocasional. Siguió tratamiento dietético y psicoterapia sin resultados satisfactorios.

Es remitido a nuestra consulta para valoración y tratamiento. La exploración física, incluyendo la exploración de raíces sacras, es normal. Se le realiza una analítica de orina, una ecografía y una radiología simple abdominal y de columna sacra, que no muestran alteraciones.

Iniciamos una pauta de vaciado fecal para control de la encopresis y administramos empíricamente oxibutinina oral a dosis inicial de 0,5 comprimidos cada $24 \mathrm{~h}$ con buena aceptación. A la semana se subió la dosis a 0,5 comprimidos cada $12 \mathrm{~h}$ y después a 1 comprimido por la mañana y medio por la noche. El objetivo era conseguir una dosis de 1 comprimido cada 8 horas, pero no fue posible ya que presentó epistaxis espontáneas y abundantes que nos obligaron a suspender la medicación.

Durante 6 meses continuamos con el control dietético, laxante y enemas para su encopresis y unas normas básicas de higiene miccional (micciones programadas cada 3 horas) para su disfunción vesical. En ese momento y dada la mala respuesta a todos los tratamientos, realizamos una cistomanometría que mostró una capacidad vesical por debajo del $40 \%$ respecto a lo esperado para su edad así como presencia de contracciones no inhibidas de hasta 100 cm de agua de presión. La micción era correcta y completa, sin obstrucción ni residuo postmiccional. Confirmado el diagnóstico de vejiga hiperactiva reintrodujimos de nuevo el tratamiento con oxibutinina. Las epistaxis espontáneas volvieron a aparecer, pero esta vez con la dosis inicial de 0,5 comprimidos cada $24 \mathrm{~h}$, por lo que fue suspendida definitivamente.

Los efectos secundarios del tratamiento con anticolinérgicos son frecuentes y bien conocidos y en el caso de los niños suelen consistir en sequedad de boca, dolor abdominal, estreñimiento, dolor de cabeza, visión borrosa y crisis de eritema facial, aunque en el prospecto del medicamento se relacionan otros muchos efectos secundarios. Suelen evitarse iniciando el tratamiento a dosis bajas nocturnas y subiendo progresivamente la dosis cada semana dependiendo de la aceptación y efecto terapéutico. En nuestra experiencia es excepcional tener que suspender la administración de oxibutinina por un efecto colateral indeseado.

Los casos encontrados en la revisión bibliográfica que ha acompañado a este trabajo son muy escasos ${ }^{1,2}$. Es en estos niños, y en aquellos con mal seguimiento de la pauta terapéutica de oxibutinina cada 8 horas, donde el uso de otros fármacos anticolinérgicos como la tolterodina o solifenacina, podría tener una indicación clara ${ }^{3}$.

\section{BIBLIOGRAFÍA}

1. Batista JE, Caffaratti J, Garat JM. Epistaxis as a side effect of oxybutynin in children: report of two cases. Neurourol Urodyn 1994; 13: 85-86.

2. Kirkali Z, WhitaKer RH. The use of oxybutynin in urological practice. Int Urol Nephrol 1987; 19: 385-391.

3. SCHRÖDER A, ThürofF JW. New strategies for medical management of overactive bladder in children. Curr Opin Urol. 2010 Jul; 20: 313317 . 